Diversity and composition of macroinvertebrate assemblages in high-altitude Tibetan streams

Laursen, Søren Kock; Hamerlik, Ladislav; Moltesen, Karen ; Christoffersen, Kirsten Seestern; Jacobsen, Dean

Published in:

Inland Waters

DOI:

10.5268/IW-5.3.818

Publication date:

2015

Document version

Publisher's PDF, also known as Version of record

Citation for published version (APA):

Laursen, S. K., Hamerlik, L., Moltesen, K., Christoffersen, K. S., \& Jacobsen, D. (2015). Diversity and

composition of macroinvertebrate assemblages in high-altitude Tibetan streams. Inland Waters, 5(3), 263-274. https://doi.org/10.5268/IW-5.3.818 


\title{
Diversity and composition of macroinvertebrate assemblages in high-altitude Tibetan streams
}

\author{
Søren Kock Laursen, ${ }^{1}$ Ladislav Hamerlik, ${ }^{2}$ Karen Moltesen, ${ }^{1}$ Kirsten Seestern Christoffersen, ${ }^{1}$ and Dean \\ Jacobsen ${ }^{1}$ \\ ${ }^{1}$ Freshwater Biological Laboratory, Department of Biology, University of Copenhagen, Copenhagen, Denmark \\ ${ }^{2}$ Department of Biology and Ecology, Faculty of Natural Sciences, Matthias Belius University, Banska Bystrica, Slovakia \\ Corresponding author: Djacobsen@bio.ku.dk
}

Received 6 January 2015; accepted 9 June 2015; published 10 July 2015

\begin{abstract}
Knowledge on the ecology of streams at extreme altitudes is relatively sparse. We conducted a preliminary survey of the macroinvertebrate fauna of Tibetan streams in June 2009 and August 2011 and compared streams with different water sources. We collected quantitative samples of macroinvertebrates and measured physicochemical variables at 16 sites ( 8 each sampling year) at altitudes ranging from 4315 to $5065 \mathrm{~m}$ a.s.l. and grouped the sites into 3 types according to origin: glacier-fed, rain-fed, and lake-outlets. We identified 38 taxa, with a mean of 8.9 taxa per site. Overall the benthic fauna was dominated by insects (71\%), mainly Diptera (especially Chironomidae). Ephemeroptera, Plecoptera, and Trichoptera were found at nearly all sites but mostly in low numbers; however, the fauna was significantly different in the 2 sampling years, especially due to the proportions of Chironomidae (68\% in June 2009 and 10\% in August 2011) and Baetidae (6\% vs. 35\%, respectively). The 3 stream types had significantly different faunas. Rain-fed streams had the highest total taxon richness ( $\gamma$-diversity), but glacier-fed streams had a slightly higher taxon turnover rate ( $\beta$-diversity). Percent glacial cover in the catchment and water turbidity explained most of the variability in taxon richness. Although not particularly taxon rich compared to other high-altitude streams, the Tibetan stream fauna showed considerable spatial variability. The fast retreat of the glaciers and permanent snow fields in Tibet makes further studies on distribution patterns and driving forces for aquatic biodiversity urgent.
\end{abstract}

Key words: alpine streams, assemblage composition, benthic fauna, glacial influence, macroinvertebrates, seasonal variability, Tibet, water source

\section{Introduction}

Alpine streams are subject to a high degree of spatial variability in the abiotic environment, partly due to the variety of possible water sources (Smith et al. 2001). Groundwater may be relatively ion- and nutrient-rich, is usually clear, and adds stability in temperature, water flow, and channel morphology (Malard et al. 1999). Surface and subsurface runoff from rainfall and snow melt varies seasonally and is a key contributor of nutrients and organic carbon from the surroundings (Uehlinger et al. 2002). Glacier-fed streams are a harsh environment (Jacobsen and Dangles 2012); they are cold, usually nutrient poor and turbid, and physically unstable, with large fluctuations in water flow (Milner and Petts 1994). In the Holarctic, species of Diamesinae (Chironomidae) are usually the only ones occupying pro-glacial reaches immediately downstream from the glacier snout, but they cannot compete with the more wide-spread species found farther downstream (Ward 1994, Milner et al. 2001). Glacier-fed streams become more benign farther downstream as the atmosphere warms the water and the stream receives tributaries from other non-glacial catchments. The ameliorating conditions downstream gradually accommodate other chironomid groups such as Orthocladiinae and, eventually, species of Ephemeroptera, 
Plecoptera, and Trichoptera (Milner and Petts 1994, Milner et al. 2001). Lakes may act as buffers against temperature and hydrological fluctuations and will typically alter the downstream faunal composition, giving rise to both higher taxon richness and densities of macroinvertebrates (Hieber et al. 2002, Maiolini et al. 2006).

In the extreme environment of glacier-fed streams, in particular near the glacier, a strong niche selection filters the species from the regional pool, leading to higher similarities and a more predictable community composition than in less extreme habitats located farther from glaciers and in non-glacial streams (Leibold et al. 2004, Chase 2007). Nevertheless, maximum $\beta$-diversity, both at the population-genetic (Finn et al. 2013) and community level (Jacobsen and Dangles 2012), was recently found in highly glaciated catchments. Glacier-fed streams thus seem to contribute to the aquatic environmental heterogeneity at the catchment level and therefore increase taxon turnover $(\beta$-diversity) and regional taxon richness ( $\gamma$-diversity; Jacobsen et al. 2012). Although local diversity ( $\alpha$-diversity) will generally increase as a result of glacial shrinkage or disappearance, a reduction of both $\beta$ - and $\gamma$-diversity at the population-genetic and community levels of biological organization is also expected (Jacobsen et al. 2012).

Most of what we know about macroinvertebrate communities in alpine streams comes from Europe (e.g., Füreder et al. 2001, Hieber et al. 2005) or North America (e.g., Ward 1986, Finn and Poff 2005), while studies from the Himalayas (Rundle et al. 1993, Suren 1994) and tropical Andes (e.g., Jacobsen 2003, Loayza-Muro et al. 2010) have provided additional insight into the organization of communities in very high-altitude ( $>3000 \mathrm{~m}$ a.s.l.) alpine streams. Although the Qinghai-Tibetan Plateau is the largest and highest plateau in the world and is surrounded by several biodiversity hot-spots (Favre et al. 2014), in terms of stream ecology and aquatic biodiversity, Tibet has virtually been a (large) white spot on the map (Jacobsen et al. 2013) until a few recent studies (Hamerlik and Jacobsen 2012, Murakami et al. 2012, Jiang et al. 2013) provided some insight into physicochemical parameters and biological communities of running waters.

Tibet is also highly affected by climate change and is currently experiencing one of the fastest increases in average temperatures outside the poles (Gautam et al. 2009). The region is witnessing a rapid change in natural vegetation, shift in crops and human land use (Wang et al. 2008), degradation of permafrost, shrinkage and/or disappearance of glaciers, and altered hydrological regime of rivers (Du et al. 2004, Yao et al. 2007). In light of this, studies on distribution patterns and driving factors of macroinvertebrate communities in Tibetan streams, in particular focusing on the effects of glacial sources, are important and timely.
Our 3 main objectives were therefore to (1) conduct a preliminary survey of the composition and diversity patterns of the macroinvertebrate fauna in Tibetan streams; (2) test for an effect of sampling time or season; (3) investigate the qualitative and quantitative differences in the fauna between streams with different water sources, comparing lake-outlets, rain-fed, and glacier-fed streams; and (4) analyze more specific relationships between the cover of glaciers in catchments and properties of the stream fauna.

\section{Methods}

\section{Study area and site selection}

Our study included 13 streams (14 sites) that are tributaries to the Brahmaputra (via Yalung and Dihang) and 2 streams within the River Salween basin (via River $\mathrm{Nu}$ ). All sites were located $28^{\circ} 22^{\prime} 32^{\prime \prime}-31^{\circ} 01^{\prime} 05^{\prime \prime} \mathrm{N}, 85^{\circ} 48^{\prime} 55^{\prime \prime}-$ $92^{\circ} 21^{\prime} 10^{\prime \prime} \mathrm{E}$, covering a large part of southeastern Tibet. Altitudes of study sites ranged from 4315 to $5065 \mathrm{~m}$ a.s.l., all above the tree line. Field work was conducted on 2 occasions: half of the sites were sampled in June 2009 (sites 1-8) and the remaining in August 2011 (sites 9-16). We selected sites to cover differences in main water source and glacial influence, including 7 sites receiving varying amounts of meltwater from glaciers located upstream in the catchment, denoted "glacier-fed" (5 sampled in 2009 and 2 in 2011), and 7 sites without glaciers in the catchment and thus fed by subsurface and surface runoff of rainwater and snowmelt, denoted "rain-fed" (3 sampled in 2009 and 4 in 2011). In addition, 2 streams with a non-glacier-fed lake placed just upstream of the sampling sites, denoted "lake-outlets," were sampled in 2011. Two sites were located along the same stream and separated by a few hundred meters; one of these sites $(1 \mathrm{G})$ was sampled in 2009 and the other $(11 \mathrm{G})$ in 2011. These sites were located downstream of a pro-glacial lake, but we treat them here as glacier-fed. We had no way of estimating ground water contribution, but this likely contributed in varying degrees to the flow at all sites.

Several indices of glacial influence on the stream environment have been developed and used to investigate the effect of glacial meltwater contribution on aquatic biodiversity. These indices have been based on percentage of glacier cover in the catchment (Füreder 2007, Milner et al. 2009), glacier size and distance from the glacier terminus (Jacobsen and Dangles 2012), percentage of meltwater contribution (Milner et al. 2006, Brown et al. 2007), or physicochemical habitat variables (Ilg and Castella 2006). Because only spot measurements of such environmental data were available, however, we preferred to estimate glacial influence simply as the distance of stream sites from the 
glacier terminus and as the percentage of glacier cover in the catchment, obtained using the software "Image J" based on topographic maps and satellite pictures in Google Earth.

\section{Field measurements and sampling}

At each site, we selected a representative reach spanning about $30 \mathrm{~m}$. Coordinates and altitude were obtained with a GPS (Garmin eTrek 10). Conductivity, temperature, and dissolved oxygen were measured with a handheld multi-probe (YSI model 6000), and turbidity was measured using a Eutech-100 turbidity meter. The mean width and depth where calculated from a series of 3-5 transversal transects, while the current velocity was estimated and categorized as either moderate $\left(\sim 0.1-0.3 \mathrm{~m} \mathrm{~s}^{-1}\right)$, fast $\left(\sim 0.3-0.6 \mathrm{~m} \mathrm{~s}^{-1}\right)$, or strong $\left(>0.6 \mathrm{~m} \mathrm{~s}^{-1}\right)$. The most abundant substrate types, stream channel stability, macrophyte cover, and periphyton biomass were estimated visually along each reach.

Macroinvertebrates were collected as 5 quantitative Surber samples $(25 \times 20 \mathrm{~cm}$; mesh size $200 \mu \mathrm{m})$ obtained from representative riffle/run habitats and preserved in $70 \%$ ethanol. In the laboratory, samples were processed using a magnifying glass, without use of subsampling. Insects were identified to family or subfamily level using available identification keys (Edington and Hildrew 1981, Elliot et al. 1988, Wallace et al. 1990, Hynes 1993) but separated into different morpho-species. Non-insects were identified to higher taxonomic levels.

\section{Data treatment}

To compensate for varying sample sizes (i.e., number of individuals in samples), we used rarefied taxon number as a measure of taxon richness, estimating the number of taxa based on the sample with the lowest number of individuals, in this case 31 . To measure the evenness of the macroinvertebrate assemblages we used Pilou's index $\left(\mathrm{J}^{\prime}\right)$. For each stream group we calculated mean local diversity ( $\alpha$-diversity) as the mean number of taxa collected per site, total or regional diversity ( $\gamma$-diversity) as the total number of taxa collected, and taxon turnover ( $\beta$-diversity) as total divided by mean local diversity. A t-test on log-transformed data was used to test for differences between univariate fauna metrics and densities of specific families/taxa between sampling campaigns.

Analyses of similarities in the taxonomic composition among localities were based on Bray-Curtis (dis)similarity on log-transformed taxon data. These data were used to perform a nonmetric multidimensional scaling (NMDS) ordination to illustrate relative differences in assemblage composition. This ordination technique has no assumptions with repect to distributions and represents samples as points in low-dimensional space, such that the relative distances among points reflects the relative similarities of samples with respect to both abundance and composition (van der Gucht et al. 2005). The NMDS goodness-of-fit was estimated with a stress function (ranges from 0 to 1 ), with values close to 0 indicating a good fit. Our interest was not to perform cluster analyses of sites, but rather to test whether our 3 a priori defined groups of glacier-fed, rain-fed, and lake-outlets showed overall differences in assemblage composition. For this we used analysis of similarities (ANOSIM), which tests the null hypothesis that within-group similarity was equal to between-group similarity. ANOSIM generates a statistical parameter R, which indicates the degree of separation between groups; a score of 1 indicates complete separation, and a score of 0 indicates no separation (van der Gucht et al. 2005).

To elucidate taxonomic relationships among the 3 stream groups, we performed similarity percentage analysis (SIMPER). This analysis gives the contribution (in percentage) of each taxon to the observed similarity between groups or samples within groups and therefore identifies the most important taxa for creating the observed pattern of similarity. Univariate metrics were calculated and multivariate analyses were conducted with Primer-e (Clarke and PRIMER 2006).

To construct a simple predictive model for taxon richness, we used ordinary least squares (OLS) model selection, using the multiple regressions integrated in the SAM software (Rangel et al. 2010). All available explanatory variables were tested against taxon count, and the most parsimonious model was identified using the lowest corrected Akaike's Information Criterion (AICc).

\section{Results}

\section{Stream site characteristics}

Catchments sizes of the study sites varied from $<6 \mathrm{~km}^{2}$ to $>400 \mathrm{~km}^{2}$, with glacial cover varying from 0 to $78 \%$ of the catchment. Stream sites covered considerable physicochemical variability in all measured parameters (Appendix 1).

\section{General patterns and temporal differences in macroinvertebrate assemblages}

We collected 8014 individuals and 38 taxa (Appendix 2). At individual stream sites, the number of taxa varied from 3 to 13 (average 8.9 per site), and the number of individuals collected ranged from 31 to 2802 in the 5 Surber samples ( 124-11208 ind $\mathrm{m}^{-2}$; Table 1). Rarefied taxon number (based on 31 individuals) ranged from 3.00 to 8.34 , and the evenness index $\left(\mathrm{J}^{\prime}\right)$ from 0.06 to 0.86 (Table 1). 
Table 1. Univariate fauna metrics for 16 Tibetan stream sites. G denotes glacier-fed sites, $R$ rain-fed sites, and L lake-outlets.

\begin{tabular}{rrrrrr}
\hline $\begin{array}{r}\text { Stream } \\
\text { Site }\end{array}$ & Sampled & $\begin{array}{r}\text { Taxon } \\
\text { Number }\end{array}$ & $\begin{array}{r}\text { Individuals } \\
\mathrm{N} \mathrm{m}^{-2}\end{array}$ & $\begin{array}{r}\text { Richness } \\
\text { Rarefaction }\end{array}$ & $\begin{array}{r}\text { Evenness } \\
\text { Pielou J' }\end{array}$ \\
\hline $\mathbf{1 G}$ & 2009 & 10 & 3404 & 4.26 & 0.50 \\
$\mathbf{2 G}$ & 2009 & 3 & 124 & 3.00 & 0.85 \\
$\mathbf{4 G}$ & 2009 & 5 & 2532 & 1.42 & 0.06 \\
$\mathbf{7 G}$ & 2009 & 7 & 824 & 5.13 & 0.53 \\
$\mathbf{8 G}$ & 2009 & 10 & 1328 & 3.97 & 0.43 \\
$\mathbf{1 1 G}$ & 2011 & 9 & 972 & 5.17 & 0.57 \\
$\mathbf{1 2 G}$ & 2011 & 10 & 388 & 8.34 & 0.86 \\
& & & & & \\
$\mathbf{3 R}$ & 2009 & 10 & 736 & 7.56 & 0.79 \\
$\mathbf{5 R}$ & 2009 & 13 & 2232 & 7.01 & 0.63 \\
$\mathbf{6 R}$ & 2009 & 11 & 11208 & 4.65 & 0.49 \\
$\mathbf{1 4 R}$ & 2011 & 9 & 1812 & 6.01 & 0.75 \\
$\mathbf{1 5 R}$ & 2011 & 10 & 2184 & 5.41 & 0.68 \\
$\mathbf{1 6 R}$ & 2011 & 8 & 528 & 5.26 & 0.48 \\
$\mathbf{9 R}$ & 2011 & 11 & 1196 & 6.15 & 0.58 \\
& & & & & \\
$\mathbf{1 0 L}$ & 2011 & 10 & 1112 & 4.15 & 0.33 \\
$\mathbf{1 3 L}$ & 2011 & 10 & 1492 & 5.40 & 0.60 \\
\hline
\end{tabular}

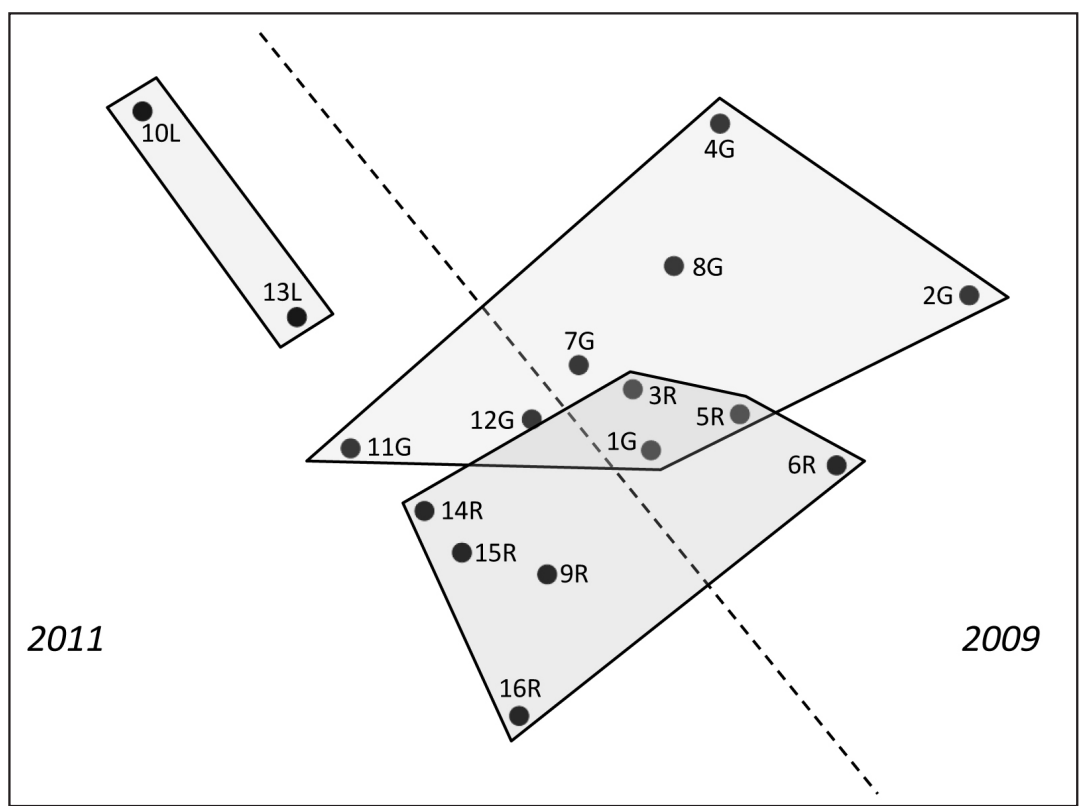

Fig. 1. NMDS ordination showing first and second axis based on Bray Curtis dissimilarities (Stress $=0.15)$ on macroinvertebrate samples $($ log transformed) from 16 Tibetan stream sites. The dashed line divides sampling years, and letters denote water source; (L) lake-outlets, (G) glacier-fed, (R) rain-fed. 
There were large differences among sites in relative abundances of taxa (Appendix 2). Overall, the fauna was dominated by insect larvae, comprising $71 \%$ of all individuals. Diptera was the most abundant group, constituting on average $47 \%$ of all individuals and $55 \%$ of the insects at each site. Of these, the chironomids were the most numerous (39\% of total and $46 \%$ of insects), and they were collected at all sites. The Orthocladiinae subfamily was the most dominant, and although Chironominae and Diamesinae were much less abundant, they distributed more evenly among the 16 sites. Oligocheates were found at 14 sites, occasionally in high numbers (average 9\% of individuals). Ephemeroptera were represented by 3 families and accounted for $21 \%$ on average of the individuals at each site (26\% of insects), mainly due to Baetidae, which occurred at 12 of the 16 sites. Plecoptera were more diverse (5 families identified) but less abundant (4\% of individuals) and were found at 12 of the 16 sites. Trichoptera were also represented by 5 families but were even more scarce (found at only 7 sites) and low in numbers ( $3 \%$ of individuals on average).

Apart from these overall patterns, there was an overall significant difference $(\mathrm{P}=0.001)$ between the 2 sampling years/seasons (Fig. 1). This temporal difference could be attributed mainly to significantly different relative proportions of Baetidae $(\mathrm{P}<0.01)$ and Chironomidae ( $\mathrm{P}<0.001$; Fig. 2). There were, however, no significant differences $(\mathrm{P}>0.05)$ between sampling years in any of the 4 univariate fauna metrics measured (Table 1). There was a clear relationship between mean local abundance of taxa and the frequency of occurrence (number of sites where specific taxa were found; Fig. 3).

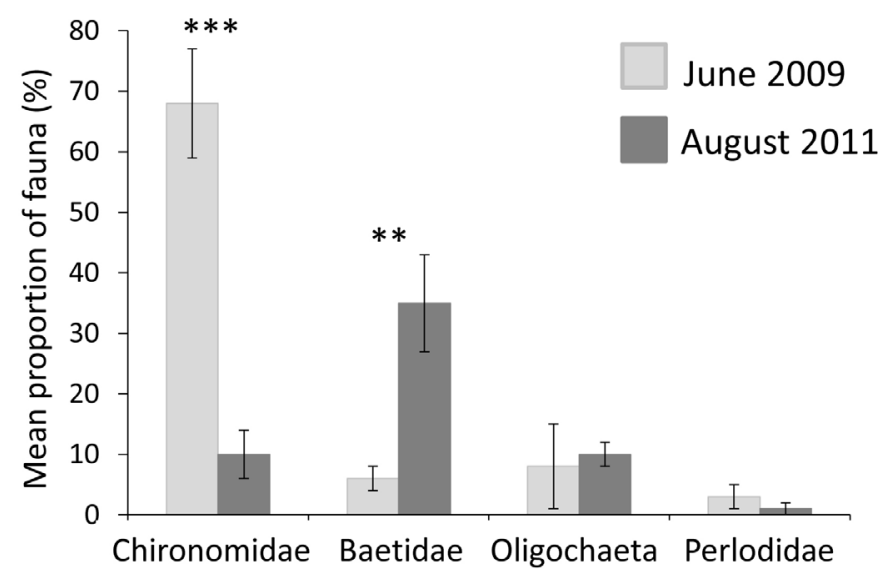

Fig. 2. Mean proportions of the taxa occurring at least at 4 of the 8 sites and with a mean proportion $>1 \%$ in one of the sampling campaigns in 2009 and 2011. Significant differences in means are indicated as $* *=\mathrm{P}<0.01$, and $* * *=\mathrm{P}<0.001$. Error bars denote SE.

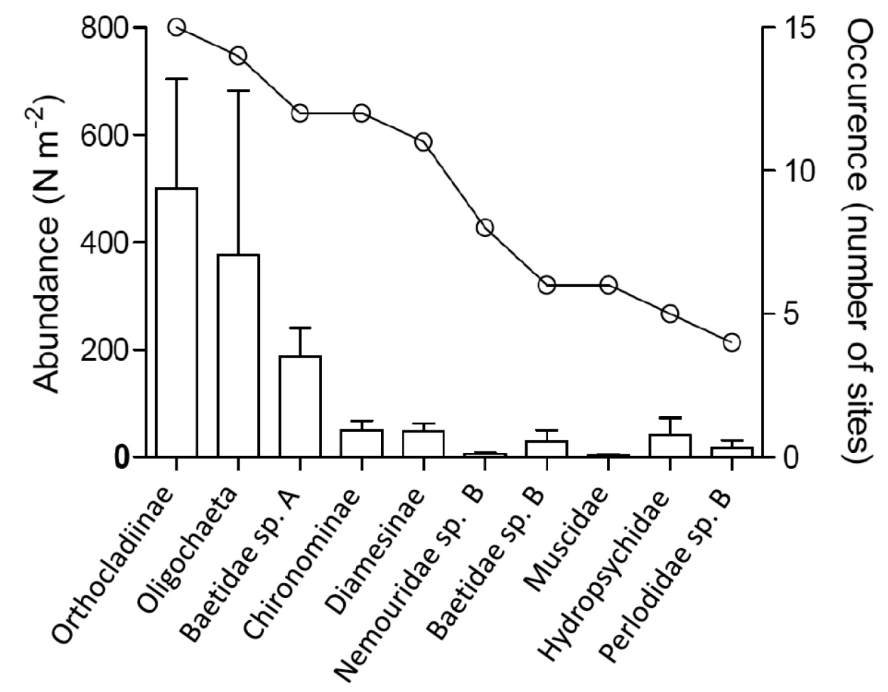

Fig. 3. Mean abundance of the 10 most common taxa (left y-axis, bars with SE) and the number of sites where they were observed (right y-axis, connected dots) in 16 Tibetan stream sites. 


\section{Stream types and macroinvertebrate assemblages}

The macroinvertebrate assemblage composition differed significantly between our a priori defined stream groups; glacier-fed vs. rain-fed $(\mathrm{P}=0.009$, ANOSIM $)$ and lake-outlet vs. either of the $2(\mathrm{P}=0.028)$, even though glacier-fed and rain-fed streams had some overlap on the NMDS 2D projection (Fig. 1).

The SIMPER analysis showed that Orthocladiinae best characterized the glacier-fed stream fauna (Table 2). Baetidae and Chironominae were important groups in the classification of both glacier-fed and rain-fed streams. Diamesinae had more explicative power in the rain-fed streams than in the 2 other stream types. Oligochaetes were important in both rain-fed streams and lake-outlets. The best overall explicative taxa in lake-outlets were Gammarus sp., Pisidium sp., and Radix peregra. The number of Orthocladiinae and oligochaetes was the main difference between glacier-fed and rain-fed streams, while mainly the presence of Gammarus sp. and Pisidium sp. set the lake-outlets apart from the 2 other stream types (Table 3). No taxa were common in one stream type and absent from the other 2 types (i.e., no taxa seemed to be exclusive to a single stream type).

Mean local taxon richness ( $\alpha$-diversity) was slightly lower in glacier-fed streams than in rain-fed and lake-outlets (Fig. 4). Rain-fed streams had the highest regional richness ( $\gamma$-diversity). Glacier-fed streams had a slightly higher $\beta$-diversity than the 2 other groups; note, however, that including only 2 true lake-outlets in the study likely led to an underestimated $\beta$-diversity and, particularly, $\gamma$-diversity for this stream group.
Table 2. SIMPER test results showing the most explanatory taxa for the differentiation of each stream type. $50 \%$ of the variation among the 3 types is explained by the given taxa.

\begin{tabular}{llll}
\hline Characteristic taxa & Glacier-fed & Rain-fed & Lake outlet \\
\hline Orthocladiinae & 38.8 & & \\
Baetidae sp. A & 19.1 & 18.6 & \\
Chironominae & 10.5 & 10.1 & \\
Diamesinae & 8.0 & 20.3 & \\
Oligochaeta & & 21.4 & 16.0 \\
Gammarus & & & 33.4 \\
Pisidium & & & 25.3 \\
Radix peregra & & & 8.4 \\
\hline
\end{tabular}

\section{Environmental variables and macroinvertebrate assemblages}

There was no correlation between altitude and any of the univariate fauna metrics or the assemblage composition (NMDS axis- 1 or axis- 2 coordinates; $\mathrm{P}>0.05$ ). Percentage glacial cover in the catchment $(\mathrm{GC} \%)$ performed best of all available environmental variables (Appendix 1) to explain the variation in the univariate fauna metrics, but the effect was only significant for raw taxon numbers, and there was no tendency of a relationship to evenness (Fig. 5). It is noteworthy that both turbidity and conductivity were inversely related to $\mathrm{GC} \%$ and inversely related to each other (Fig. 6).

A multiple regression of turbidity and $\mathrm{GC} \%$ provided a significantly better predictor of taxon number than any single environmental variable ( $\mathrm{SP}_{\text {est }}$; Fig. 7). None of the remaining variables in Appendix 1 improved the model without increasing AICc or showing collinearity.

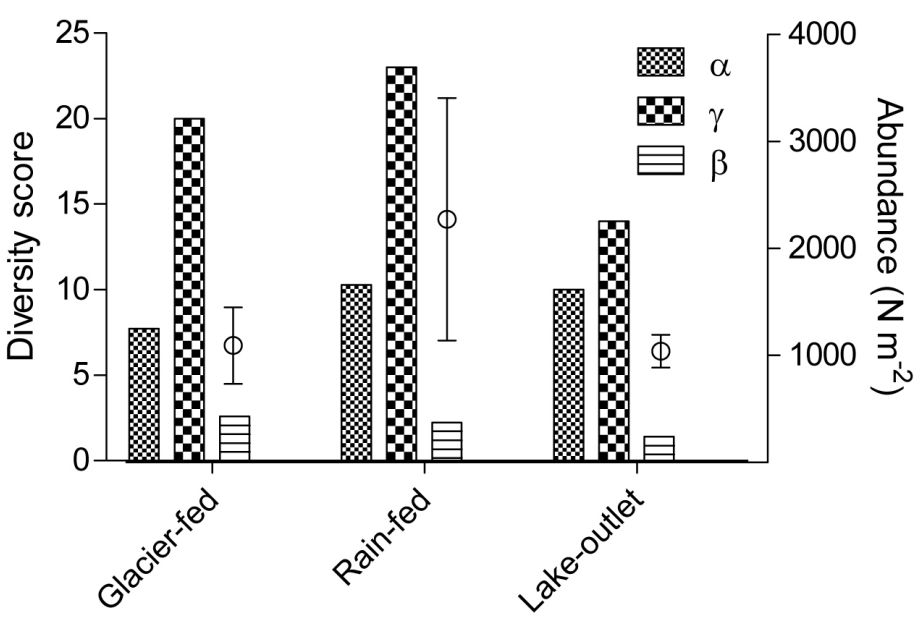

Fig. 4. Average abundances (right y-axis, squares) and $\alpha, \beta$, and $\gamma$ diversities (left y-axis, bars) of macroinvertebrates in 16 Tibetan stream sites of 3 types: glacier-fed, rain-fed, and lake-outlets. Error bars denote SE on abundances. 
Table 3. SIMPER results of $50 \%$ of the taxa dissimilarities between the different stream types.

\begin{tabular}{lccc}
\hline Taxon & $\begin{array}{c}\text { Glacier-fed vs. } \\
\text { rain-fed }\end{array}$ & $\begin{array}{c}\text { Glacier-fed vs. } \\
\text { lake outlet }\end{array}$ & $\begin{array}{c}\text { Rain-fed vs. } \\
\text { lake outlet }\end{array}$ \\
\hline Orthocladiinae & 10.6 & & \\
Oligochaeta & 9.4 & & \\
Baetidae sp. A & 7.8 & & \\
Elmidae & 6.8 & & \\
Diamesinae & 6.2 & & \\
Chironominae & 6.2 & & \\
Simuiliidae & 5.9 & 16.5 & \\
\hline Gammarus & & 11.7 & \\
Pissidium & & 9.4 & \\
Orthocladiinae & & 8.7 & \\
Baetidae sp. A & & 5.8 & \\
Gyraulus & & & 7.0 \\
\hline Gammarus & & & 7.1 \\
Pissidium & & & \\
Diamesinae & & & \\
Baetidae sp. A & & & 4.9 \\
Orthocladiinae & & & \\
Elmidae & & & \\
Chironominae & & & \\
\hline & & & \\
\hline
\end{tabular}
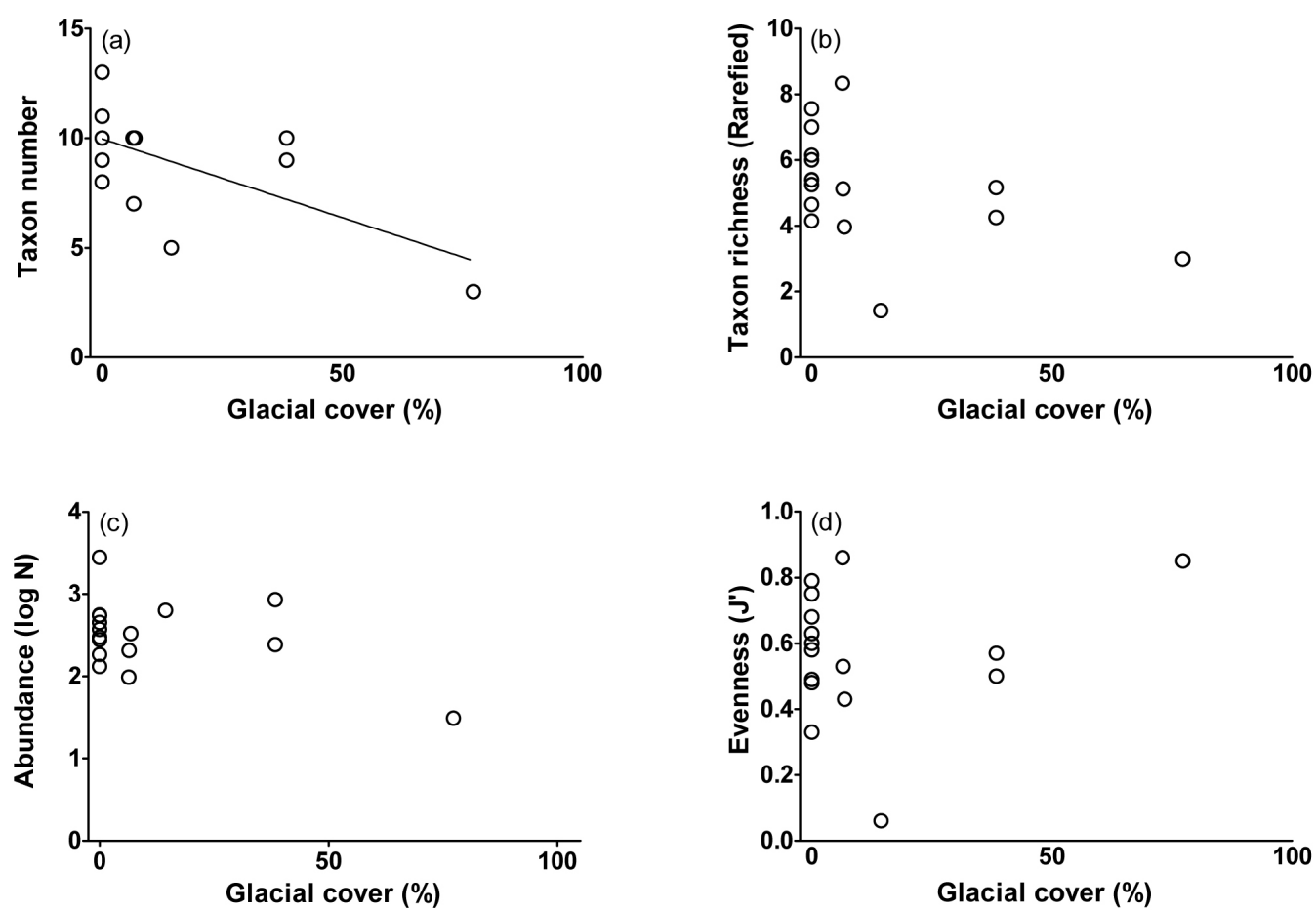

Fig. 5. (a) Taxon richness, (b) rarefied taxon number, (c) abundance (log transformed), and (d) evenness of benthic macroinvertebrates in 16 Tibetan stream sites as a function of percent glacier cover in the catchment. The linear regression line for taxon number: $\mathrm{R}^{2}=0.415 ; \mathrm{P}=0.007$. 

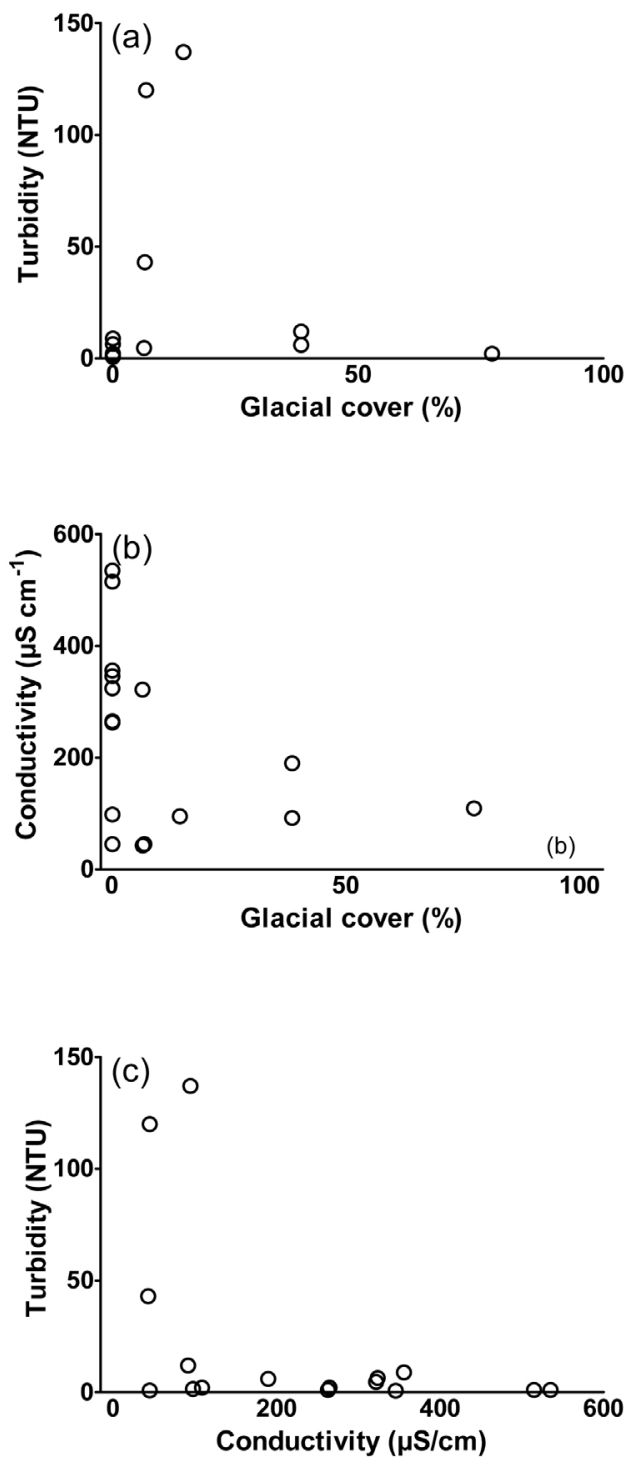

Fig. 6. Turbidity and conductivity in 16 Tibetan stream sites as a function of the percentage of glacier cover in the catchment.

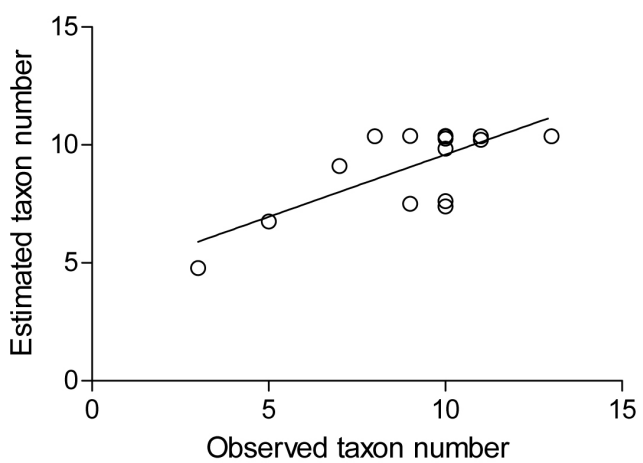

Fig. 7. Estimated taxon number as a function of observed taxon number calculated from a combination of glacial cover in the catchment $(\mathrm{GC} \%)$ and turbidity $(\mathrm{T})$ : Taxaest $=10.391-0.072[\mathrm{GC}$ $\%]-0.019[\mathrm{~T}]$. The linear regression: $\mathrm{R}^{2}=0.530 ; \mathrm{P}=0.001$.

\section{Discussion}

\section{General patterns and temporal differences in macroinvertebrate assemblages}

The most widespread taxa were also the most locally abundant, a commonly observed distribution pattern of organisms in general (Brown 1984, Gaston 1996) as well as in high altitude streams (Jacobsen and Terneus 2001, Jacobsen and Marín 2008). Overall, the benthic macroinvertebrate fauna was dominated by insects, with the Chironomidae (specifically the Orthocladiinae subfamily) as the most abundant. Although we collected Ephemeroptera, Plecoptera, and Trichoptera taxa at most sites, these were found only in relatively small numbers compared to the chironomids; however, the composition of the fauna differed significantly between sampling campaigns, mainly due to relative proportions of some of the importance families: Chironomidae (68\% in June 2009 and $10 \%$ in August 2011) and Baetidae (6\% vs. 35\%, respectively). Thus, our results agree with those obtained in 2 other recent studies on Tibetan streams, both with collections performed in August. Murakami et al. (2012) sampled 6 glacier-fed sites at $4700-5100 \mathrm{~m}$ a.s.l. and found ephemeropterans contributed $45 \%$ and chironomids $27 \%$ of total insect abundance. Jiang et al. (2013) sampled 7 sites at $3670 \mathrm{~m}$ a.s.l., where chironomids made up $22 \%$ of the total fauna while ephemeropterans and trichopterans contributed $32 \%$ and $29 \%$, respectively. The much lower percentage of trichopterans found in our study ( $7 \%$ and $1 \%$ in the 2 sampling campaigns) is probably due to the considerably lower altitude of our sites.

As expected for streams at high altitudes (Jacobsen 2008), macroinvertebrate richness was low in the Tibetan streams. We found 32 different families or higher taxonomic groups, 8.2 per site. This finding is in accordance with the 2 recent studies from Tibetan streams with comparable taxonomic resolution; a mean of 9 taxa (2-14) were collected in the 6 glacier-fed streams (Murakami et al. 2012), and 20 total taxa were reported from the 7 slightly lower sites (Jiang et al. 2013). These values also correspond well with Nepalese Himalayan streams, where Brewin et al. (1995) reported a mean of 6 taxa per site for streams at $3800-4320 \mathrm{~m}$ a.s.l., while Suren (1994) found a mean of 16.7 taxa in streams at 4000-4250 m a.s.l., but in Suren (1994) the chironomids were identified to 15 different genera and subfamilies. Further, the mean taxonomic richness that we found in the present study is largely similar to a mean taxon richness (also mainly family) of 10.6 per site (only including Surber samples; excluding qualitative samples, as in the present study) reported from Andean streams 3800-4000 m a.s.l. on the Bolivian Altiplano (Jacobsen 
and Marín 2008). In contrast, Andean streams 3900-4200 m a.s.l. in Ecuador, sampled with exactly the same method and effort as we used in Tibet, had an average family richness of 21.8 (Jacobsen et al. 2012). The Tibetan streams thus seem to follow the "norm" for macroinvertebrate richness of very high-altitude streams, while the environmentally heterogeneous conditions of the equatorial "páramo" of Ecuador seem to promote exceptionally high aquatic diversity.

\section{Stream type and macroinvertebrate assemblages}

Despite the large variability in glacial influence within the glacier-fed stream group, the 3 stream types formed significantly different groups based on their macroinvertebrate assemblages. Nevertheless, this result is in accordance with studies from the European Alps (Brown et al. 2003, Hieber et al. 2005) and the Ecuadorian Andes (Jacobsen 2008). In particular, the importance of lakes for downstream faunas, through their moderating effect on physical instability and environmental harshness of highmountain streams, has previously been demonstrated (Hieber et al. 2002).

The lower mean local $(\alpha)$ and regional $(\gamma)$ diversity but higher taxon turnover rate ( $\beta$-diversity) in glacier-fed streams also largely confirms earlier studies (Hamerlik and Jacobsen 2012, Jacobsen et al. 2012, Jacobsen and Dangles 2012) and demonstrates how glacial runoff contributes to environmental heterogeneity in alpine catchments; however, macroinvertebrate assemblages in these temperate/subtropical streams are most likely subject to seasonal changes due to phenology as well as interannual variability. The overall significant effect of sampling year (2009 vs. 2011) and/or season (June vs. August) on assemblages, in concert with differing number of sites in each stream group in the 2 sampling campaigns, potentially flaws such comparisons. So, although there were no significant differences in any of the univariate fauna metrics between sampling years, these results should be interpreted with caution.

Glacier-fed streams were generally dominated by chironomids, especially Orthocladiinae. Only the site closest to the glacier snout (site $2 \mathrm{G}$ ) as well as one of the more unstable glacier-fed streams (site 12G) showed a higher abundance of Diamesinae. Although Diamesinae is normally associated with pro-glacial stream reaches (Ward 1994, Milner et al. 2001), the presence of this subfamily better defined rain-fed streams in the SIMPER analysis, probably because most of our glacier-fed streams sites were located several kilometers from the glaciers. The lake-outlets were separated from the other stream types by the presence of Gammarus sp., Radix sp., and Pisidium sp. These groups are mainly shredders, scrapers, and filterers respectively (Merritt and Cummins 1996), and their abundance indicates that the lakes included in this study act as sources of particulate carbon as food for downstream reaches (Hieber et al. 2002, Maiolini et al. 2006). In addition, lake-outlets also have higher hydrological stability (Hieber et al. 2002), allowing establishment of rooted macrophytes, which serve as habitat and food (indirectly as well as directly) for detritivores and herbivore shredders and scrapers (Jacobsen 2008). Macrophytes were abundant in the 2 non-glacial lake outlets but scarce in all other sites.

\section{Glacial influence and macroinvertebrate assemblages}

Glacial cover in the catchment had a uniform, negative effect on the number of both taxa and abundance of macroinvertebrates, a well-known pattern from a multitude of studies on longitudinal trends in invertebrate communities (e.g., Maiolini and Lencioni 2001, Robinson et al. 2001, Jacobsen et al. 2010). Nevertheless, recent studies have reported humped-shaped relationships between taxon richness and glacier cover in the catchment (Jacobsen et al. 2012, Cauvy-Fraunié et al. 2014). This pattern might also be the case in the Tibetan streams, but determination would have required a higher data density to be detected (i.e., a greater number of sites along the glacial gradient).

A better taxonomic identification of the chironomids conducted in 2009 as part of our survey (Hamerlik and Jacobsen 2012) revealed that Diamesa did become more common close to the glacier snout. A single species of Diamesa and a species of Chaetocladius genus were only found close to the glacier margins in that survey, suggesting that these species could be threatened by glacial retreat. In the present study, however, we could not identify any taxa that seemed to be restricted to glacier-fed streams, as has been shown in locations such as Montana, USA (Stagliano et al. 2007, Muhlfeld et al. 2011), the Pyrenées (Brown et al. 2007), and Ecuador (Espinosa et al. 2010), but this again may be related to our relatively coarse-level taxonomic resolution, particularly with respect to the chironomids, or long distances from the glaciers that characterize most of our samples sites. More research is needed to examine the endemic species in Tibetan glacier-fed streams to confirm this.

The multiple regression model accurately predicted the taxon number from a combination of glacial cover and turbidity. Turbidity tended to be negatively related to glacial cover in the catchment, and several of our streams close to glaciers were crystal clear. This finding is in contrast to most other studies reporting high mean levels of glacially derived suspended solids, and hence turbidity, in glacier-fed streams (e.g., Milner et al. 2001, Kuhn et al. 
2011), and turbidity is even included in glaciality indices (Ilg and Castello 2006). Not only glacial flour contributes to turbidity, however; any type of erosion in the catchment, natural or from anthropogenic activities, will increase turbidity. The 2 sites with the highest turbidities (sites $4 \mathrm{G}$ and $8 \mathrm{G}$ ) were located far from the glaciers, and elevated suspended sediment loads seemed to be derived from other than current glacial processes. There is ample evidence for the detrimental effect of fine suspended sediments on abundance and diversity of macroinvertebrates in connection with various land-use changes (Wood and Armitage 1997, Fossati et al. 2001, Wantzen 2006).

\section{Conclusion}

This preliminary survey has shown that although the Tibetan stream macroinvertebrate fauna is relatively taxon-poor, there is a considerable variety of stream types and benthic communities. We were only able to perform spot measurements of a few environmental variables; hence, our ability to identify regulating factors was relatively weak. In addition, fish such as stone loaches (Triplophysa) were widespread and locally abundant (Jacobsen et al. 2013), and their possible interaction with macroinvertebrates should be studied further. Because glacier-fed streams are a prominent contributor to the variability in aquatic habitats and biodiversity, the ongoing shrinkage of glaciers can be anticipated to have widespread effects on Tibetan running waters and their biological communities. To monitor and document these effects, more studies are needed on environmental driving factors and species distribution patterns, particularly focusing on the endemics of glacier-fed streams because these might serve as sentinels of climate changes.

\section{Acknowledgements}

The technical lab assistance from Anne J. Jacobsen is appreciated. We are grateful to Anders Kjær, Lars Christensen, Zhu Bin, and the Innovation Centre Denmark, Shanghai, for invaluable assistance in planning and arranging the expeditions to Tibet. This study was made possible by a Carlsberg foundation grant no 200201-0444 to KSC and DJ.

\section{References}

Brewin PA, Newman TLM, Ormerod SJ. 1995. Patterns of macroinvertebrate distribution in relation to altitude, habitat structure and land use in streams in the Nepalese Himalaya. Arch Hydrobiol. 135:79-100.

Brown JH. 1984. On the relationship between abundance and distribution of species. Am Nat. 124:255-279.
Brown LE, Hannah DM, Milner AM. 2003. Alpine stream habitat classification: an alternative approach incorporating the role of dynamic water source contributions. Arct Antarct Alp Res. 35:313-322.

Brown LE, Hannah DM, Milner AM. 2007. Vulnerability of alpine stream biodiversity to shrinking glaciers and snowpacks. Glob Change Biol. 13:958-966.

Cauvy-Fraunié S, Espinosa R, Andino P, Dangles O, Jacobsen D. 2014. Relationships between stream macroinvertebrate communities and new flood-based indices of glacial influence. Freshw Biol. doi: 10.1111/fwb. 12395

Chase JM. 2007. Drought mediates the importance of stochastic community assembly. P Nat Acad Sci. 104:17430-17434.

Clarke K, PRIMER GR. 2006. V6: user manual/tutorial. Primer-E Ltd, Plymouth.

Du M, Kawashima S, Yonemura S, Zhang X, Chen S. 2004. Mutual influence between human activities and climate change in the Tibetan Plateau during recent years. Global Planet Change. 41:241-249.

Edington JM, Hildrew AG. 1981. Caseless caddis larvae of the British Isles. Ambleside, Cumbria, (UK): Freshwater Biological Association.

Elliott JM, Humpesch UH, Macan TT. 1988. Larvae of the British Ephemeroptera. Ambleside, Cumbria (UK): Freshwater Biological Association.

Espinosa R, Andino P, Jacobsen D. Dangles O. 2010. Fauna acuática en la Reserva Ecológica Antisana. Quito (EC): Pontificia Universidad Católica del Ecuador-IRD-Universidad de Copenhague.

Favre A, Päckert M, Pauls ST, Jähnig SC, Uhl D, Michalak I. MuellnerRiehl AN. 2014. The role of the uplift of the Qinghai-Tibetan Plateau for the evolution of Tibetan biotas. Biol Rev. doi: 10.1111/brv.12107

Finn DS, Khamis K, Milner AM. 2013. Loss of small glaciers will diminish beta diversity in Pyrenean streams at two levels of biological organization. Glob Ecol Biogeogr. 22:40-51.

Finn DS, Poff NL. 2005. Variability and convergence in benthic communities along the longitudinal gradients of four physically similar Rocky Mountain streams. Freshw Biol. 50:243-261.

Fossati O, Wasson JG, Hery C, Salinas G, Marin R. 2001. Impact of sediment releases on water chemistry and macroinvertebrate communities in clear water Andean streams (Bolivia). Arch Hydrobiol. 151:33-50.

Füreder L. 2007. Life at the edge: habitat condition and bottom fauna of alpine running waters. Int Rev Hydrobiol. 92:491-513.

Füreder L, Schütz C, Wallinger M, Burger R. 2001. Physico-chemistry and aquatic insects of a glacier-fed and a spring-fed alpine stream. Freshw Biol. 46:1673-1689.

Gaston KJ. 1996. The multiple forms of the interspecific abundancedistribution relationship. Oikos. 76:211-220.

Gautam R, Hsu N, Lau KM, Tsay SC, Kafatos M. 2009. Enhanced pre-monsoon warming over the Himalayan-Gangetic region from 1979 to 2007. Geophys Res Lett. 36(7).

Hamerlik L, Jacobsen D. 2012. Chironomid (Diptera) distribution and diversity in Tibetan streams with different glacial influence. Insect Conserv Divers. 5:319-326. 
Hieber M, Robinson CT, Uehlinger U, Ward JV. 2002. Are alpine lake outlets less harsh than other alpine streams? Arch Hydrobiol. 154:199-223.

Hieber M, Robinson CT, Uehlinger U, Ward JV. 2005. A comparison of benthic macroinvertebrate assemblages among different types of alpine streams. Freshw Biol. 50:2087-2100.

Hynes HBN. 1993. A key to the adults and nymphs of the British stoneflies (Plecoptera). Ambleside, Cumbria (UK): Freshwater Biological Society.

Ilg C, Castella E. 2006. Patterns of macroinvertebrate traits along three glacial stream continuums. Freshw Biol. 51:840-853.

Jacobsen D. 2003. Altitudinal changes in diversity of macroinvertebrates from small streams in the Ecuadorian Andes. Arch Hydrobiol 158:145-167.

Jacobsen D. 2008. Tropical high-altitude streams. In: Dudgeon D, editor. Tropical stream ecology. London: Elsevier. p. 219-253.

Jacobsen D, Dangles O, Andino P, Espinosa R, Hamerlik L, Cadier E. 2010. Longitudinal zonation of macroinvertebrates in an Ecuadorian glacier-fed stream: do tropical glacial systems fit the temperate model? Freshw Biol. 55:1234-1248.

Jacobsen D, Dangles O. 2012. Environmental harshness and global richness patterns in glacier-fed streams. Glob Ecol Biogeogr. 21:647-656.

Jacobsen D, Laursen SK, Hamerlik L, Hansen KM, Tsering T, Zhu B. 2013. Sacred fish: on beliefs, fieldwork, and freshwater food webs in Tibet. Front Ecol Environ. 11:50-51.

Jacobsen D, Marín R. 2008. Bolivian Altiplano streams with low richness of macroinvertebrates and large diel fluctuations in temperature and dissolved oxygen. Aqua Ecol. 42:643-656.

Jacobsen D, Milner AM, Brown LE, Dangles O. 2012. Biodiversity under threat in glacier-fed river systems. Nat Clim Change. 2:361-364.

Jacobsen D, Terneus E. 2001. Aquatic macrophytes in cool aseasonal and seasonal streams: a comparison between Ecuadorian highland and Danish lowland streams. Aqua Bot. 71:281-295.

Jiang X, Xie Z, Chen Y. 2013. Longitudinal patterns of macroinvertebrate communities in relation to environmental factors in a TibetanPlateau river system. Quat Int. 304:107-114.

Kuhn J, Andino P, Calvez R, Espinosa R, Hamerlik L, Vie S, Dangles O, Jacobsen D. 2011. Spatial variability in macroinvertebrate assemblages along and among neighbouring equatorial glacier-fed streams. Freshw Biol. 56:2226-2244.

Leibold MA, Holyoak M, Mouquet N, Amarasekare P, Chase J, Hoopes M, Holt R, Shurin J, Law R, Tilman D. 2004. The metacommunity concept: a framework for multi-scale community ecology. Ecol Lett. 7:601-613.

Loayza-Muro RA, Elías-Letts R, Marticorena-Ruíz JK, Palomino EJ, Duivenvoorden JF, Kraak MHS, Admiral W. 2010. Metal-induced shifts in benthic macroinvertebrate community composition in Andean high altitude streams. Environm Toxicol Chem. 29:27612768.

Maiolini B, Lencioni V. 2001. Longitudinal distribution of macroinvertebrate assemblages in a glacially influenced stream system in the
Italian Alps. Freshw Biol 46:1625-1639.

Maiolini B, Lencioni V, Boggero A, Thaler B, Lotter A, Rossaro B. 2006. Zoobenthic communities of inlets and outlets of high altitude Alpine lakes. Hydrobiologia. 562:217-229.

Malard F, Tockner K, Ward JV. 1999. Shifting dominance of subcatchment water sources and flow paths in a glacial floodplain, Val Roseg, Switzerland. Arct Antarct Alp Res. 3:135-150.

Merritt RW, Cummins KW. 1996. Trophic relations of macroinvertebrates. In: Hauer FR, Lamberti GA, editors. Methods in stream ecology. San Diego (CA): Academic Press. p. 453-474.

Milner AM, Brittain JE, Castella E, Petts GE. 2001. Trends of macroinvertebrate community structure in glacier-fed rivers in relation to environmental conditions: a synthesis. Freshw Biol. 46:1833-1847.

Milner AM, Brown LE, Hannah DM. 2009. Hydroecological response of river systems to shrinking glaciers. Hydrol Proc. 23:62-77.

Milner AM, Conn SC, Brown LE. 2006. Persistence and stability of macroinvertebrate communities in streams of Denali National Park, Alaska: implications for biological monitoring. Freshw Biol. 51:373-387.

Milner AM, Petts GE. 1994. Glacial rivers: physical habitat and ecology. Freshw Biol. 32:295-307.

Muhlfeld CC, Giersch JJ, Hauer FR, Pederson GT, Luikart G, Peterson DP, Downs CC, Fagre DB. 2011. Climate change links fate of glaciers and an endemicalpine invertebrate. Clim Change. 106:337-345.

Murakami T, Hayashi Y, Minami M, Wang J, Torii T, Fujitani T, Yoshinari G, Zhu L, Nishimura M. 2012. Limnological features of glacier-fed rivers in the Southern Tibetan Plateau, China. Limnology. 13:301-307.

Rangel TF, Diniz-Filho JAF, Bini LM. 2010. SAM: a comprehensive application for spatial analysis in macroecology. Ecography. 33:46-50.

Robinson C, Uehlinger U, Hieber M. 2001. Spatio-temporal variation in macroinvertebrate assemblages of glacial streams in the Swiss Alps. Freshw Biol. 46:1663-1672.

Rundle SD, Jenkins A, Ormerod S. 1993. Macroinvertebrate communities in streams in the Himalaya, Nepal. Freshw Biol. 30:169-180.

Smith BP, Hannah DM, Gurnell AM, Petts GE. 2001. A hydrogeomorphological context for ecological research on alpine glacial rivers. Freshw Biol. 46:1579-1596.

Stagliano DM, Stephens GM, Bosworth WR. 2007. Aquatic invertebrate species of concern on USFS Northern Region lands. USDA Forest Service.

Suren AM. 1994. Macroinvertebrate communities of streams in western Nepal: effects of altitude and land use. Freshw Biol. 32:323-336.

Uehlinger U, Tockner K, Malard F. 2002. Ecological windows in glacial stream ecosystems. Eawag News. 54:20-21.

van der Gucht K, Vandekerckhove T, Vloemans N. 2005. Characterization of bacterial communities in four freshwater lakes differing in nutrient load and food web structure. Microb Ecol. 53:205-220.

Wallace ID, Wallace B, Philipson GN. 1990. Case-bearing caddis larvae of Britain and Ireland. Ambleside, Cumbria (UK): Freshwater Biological Society. 
Wang XD, Zhong XH, Liu SZ, Liu JG, Wang ZY, Li MH. 2008. Regional assessment of environmental vulnerability in the Tibetan Plateau: development and application of a new method. J Arid Environ. 72:1929-1932.

Wantzen KM. 2006. Physical pollution: effects of gully erosion on benthic invertebrates in a tropical clear-water stream. Aquat Conserv. 16:733-749.

Ward JV. 1986. Altitudinal zonation in a Rocky mountain stream. Arch Hydrobiol (Suppl). 74:133-199.

Ward JV. 1994. Ecology of alpine streams. Freshw Biol. 32:277-294.

Wood PJ, Armitage PD. 1997. Biological effects of fine sediment in the lotic environment. Environ Manage. 21:203-217.
Yao T, Pu J, Lu A, Wang Y, Yu W. 2007. Recent glacial retreat and its impact on hydrological processes on the Tibetan Plateau, China, and surrounding regions. Arct Antarct Alp Res. 39:642-650.

\section{Supplementary Material}

Supplementary Material is available for download via the Inland Waters website, https://www.fba.org.uk/journals/index.php/IW:

Appendix 1 and 2 . 